\title{
Higher balanced solution use is associated with less severe kidney injury and mortality: a mimic 2 analysis
}

\author{
FG Zampieri ${ }^{1}{ }^{2 *}$, OT Ranzani ${ }^{3}$, IDS Martins ${ }^{4}$, AB Libório $^{4}$ \\ From ESICM LIVES 2015 \\ Berlin, Germany. 3-7 October 2015
}

\begin{abstract}
Introduction
Balanced solutions may be associated with lower morbidity in critical illness in comparison with chloride-rich solutions, including acute kidney injury (AKI). Lactated ringer (LR) is one of most widely used balanced solutions. Nevertheless, it is unclear if fluid mix during the first days of ICU admission influences the development of AKI after controlling for other relevant confounders such as fluid balance, illness severity and comorbidities.
\end{abstract}

\section{Objectives}

To assess the association between the higher percentages of fluid administered as LR (\%LR) in the first 48 hours of ICU stay and the risk of developing severe AKI (KDIGO II/III) during the first 7 of ICU stay. As secondary endpoint, we assessed the impact of \%LR in hospital mortality.

\section{Methods}

Data were extracted from MIMIC-2 database, which contain information from more than 32,000 patients. All infused volume of $\mathrm{LR}, \mathrm{NaCl} 0.45 \%, \mathrm{NaCl} 0.9 \%, \mathrm{NaCl} 3 \%$ and glucose $5 \%$ were retrieved from the database. \%LR was calculated as total amount of LR infused/total amount of fluid infused. Data were adjusted for illness severity (SAPS 1), fluid balance, ICU type, age, gender and major comorbidities. Patients with chronic kidney disease (admission creatinine higher than $4 \mathrm{mg} / \mathrm{dL}$ ) and with short $(<48 \mathrm{~h})$ ICU stay were excluded. Analysis was performed through logistic regression.

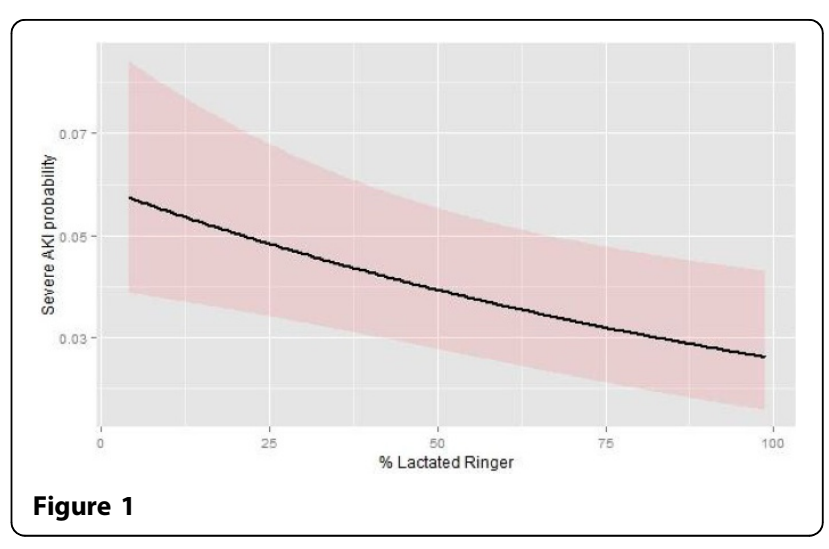

\section{Results}

After all inclusion criteria were required, 4295 patients remained in the final analysis and 334 (7\%) patients developed severe AKI and 352 (8\%) died during hospital stay. Increasing \%LR was associated with lower incidence of severe AKI (shown in Figure 1, OR 0.91; 95\% CI $0.86-0.97$ for each $10 \%$ increase) and with lower hospital mortality (OR 0.82 , 95\% CI $0.77-0.87$ for each $10 \%$ increase).

Other factors associated with severe AKI development were SAPS (OR 1.11 for each point increase, 95\% CI 1.08-1.15), upper quartile of fluid balance (OR 3.08, 95\% CI 2.12-4.51), presence of liver disease (OR 2.20, 95\% CI 1.31-3.69), presence of heart failure (OR 1.77, 95\% CI 1.31-2.38) and admission to a surgical ICU (OR 2.06, 95\% CI 1.47-2.88).

\section{Conclusions}

Higher \%LR is independently associated with lower AKI and lower mortality in a wide population of critically ill patients. These findings corroborate to the concept that 
balanced solutions should be the preferred fluid type in the critically ill.

\section{Authors' details}

${ }^{1}$ Hospital das Clínicas, Intensive Care Unit, São Paulo, Brazil. ${ }^{2}$ Hospital Alemão Oswaldo Cruz, Intensive Care Unit, São Paulo, Brazil. ${ }^{3}$ Hospital das Clínicas, University of São Paulo, Respiratory Intensive Care Unit, São Paulo, Brazil. ${ }^{4}$ Faculdade de Medicina da Universidade do Ceará, Programa de Pósgraduação em Ciência Médicas, Fortaleza, Brazil.

Published: 1 October 2015

\section{Reference}

1. Yunos NM, Bellomo R, Hegarty C: Association between a chloride-liberal vs chloride-restrictive intravenous fluid administration strategy and kidney injury in critically ill adults. JAMA 2012, 17(308(15)):1566-72, Oct. doi: 10.1001/jama.2012.13356.

doi:10.1186/2197-425X-3-S1-A15

Cite this article as: Zampieri et al:: Higher balanced solution use is associated with less severe kidney injury and mortality: a mimic 2 analysis. Intensive Care Medicine Experimental 2015 3(Suppl 1):A15.

\section{Submit your manuscript to a SpringerOpen ${ }^{\circ}$ journal and benefit from:}

- Convenient online submission

- Rigorous peer review

- Immediate publication on acceptance

- Open access: articles freely available online

- High visibility within the field

- Retaining the copyright to your article 